Çukurova Üniversitesi Mühendislik Mimarlık Fakültesi Dergisi, 33(3), ss. 255-262, Eylül 2018

\title{
Hidrojen ile Yakıt Zenginleştirmenin Dizel Motorun Motor Performansı ve Emisyon Özelliklerine Etkisi
}

\author{
Ahmet ÇALIK*1 \\ ${ }^{1}$ Mersin Üniversitesi, Teknik Bilimler Meslek Yüksekokulu, Makine, Mersin
}

Geliş tarihi: 20.07.2018～Kabul tarihi: 15.10.2018

$\ddot{O} z$

Hava kirliliğinin giderek artışı ve motor performansı arttırmaya yönelik arayışlar hidrojen gibi ek yakıtlara olan ihtiyacı artırmıştır. Bu çalışmada, bir sıkıştırma ateşlemeli motorun çalışma karakteristikleri üzerine atık kızartma yağından üretilen biyodizel yakıtına (AKY) hidrojen ilavesinin etkileri deneysel olarak incelenmiştir. Hidrojen, giriş havasına belli bir debide verilmiştir. Yapılan testte dizel motorunun performans ve emisyon değerleri incelenmiştir. Katkısız dizel yakıt, motorun çeşitli yakıtlara göre operasyonel özelliklerini karşılaştırmak için referans yakıt olarak seçilmiştir. Sonuç olarak hidrojen ilavesinin motor performansını artırdığını gözlemlenmiştir. Hidrojen gazı motor silindirlerine verildiğinde $\mathrm{CO}$ ve $\mathrm{CO}_{2}$ emisyonları azalmış ve $\mathrm{NO}_{x}$ emisyonları ise artmıştır.

Anahtar Kelimeler: Hidrojen, Biyodizel, Performans, Emisyon

\section{Effect of Fuel Enrichment with Hydrogen on Engine Performance and Emission Characteristics of Diesel Engine}

\begin{abstract}
Increase in air pollution and seeking to improve engine performance has increased the need for additional fuels such as hydrogen. In this study, the effects of hydrogen addition on biodiesel fuel produced from waste frying oil on the operating characteristics of an ignition engine have been experimentally investigated. Hydrogen is introduced into the inlet air at a certain flow rate. Performance and emission values of the diesel engine were examined. Pure diesel fuel is selected as the reference fuel to compare the operational characteristics of the engine with respect to various fuels. As a result, it has been observed that the hydrogen addition increases the engine performance. When hydrogen gas is supplied to engine cylinders, $\mathrm{CO}$ and $\mathrm{CO}_{2}$ emissions are reduced and $\mathrm{NOx}$ emissions are increased.
\end{abstract}

Keywords: Hydrogen, Biodiesel, Performance, Emissions

*Sorumlu yazar (Corresponding author): Ahmet ÇALIK, ac@mersin.edu.tr 


\section{GİRIS}

Ulaşımdan güç üretimine kadar birçok alanda yaygın olarak kullanılmakta olan içten yanmalı motorlar araştırmacılarının ilgisini çekmeye devam etmektedir. İçten yanmalı motorlardan olan dizel motorlar yüksek enerji verimliliği, yüksek stabilite ve çeșitli çalışma koşulları için esnek olma gibi önemli avantajlara sahip olduklarından pek çok araştırmaya konu olmuştur [1-5].

Günümüzde, içten yanmalı motorlar konvansiyonel petrol bazlı yakıtlara oldukça bağımlıdırlar. $\mathrm{Bu}$ bağımlılık, geleneksel yakıtların, artan nüfus ve sanayileşme nedeniyle kıtlık sorunuyla karşı karşıya kalması nedeniyle kaçınılmaz problemler yaratmaktadır. $\mathrm{Bu}$ nedenle, araştırmacılar fosil yakıtlara yenilenebilir, sürdürülebilir ve temiz alternatifler bulmaya çalışıyorlar. Fosil yakıtların tükenmesinin yanı sıra, zararlı emisyon yaymaları da bilim insanlarını yeni alternatifleri araştırmaya zorladi [6-9].

Biyodizel çeşitli hammaddeden üretilebilir. Genel olarak, hammaddeler yenilebilir veya yenmeyen bitkisel yağ, atık veya geri dönüştürülmüş yağ ve hayvansal yağlar olarak sıralanabilir $[1,10]$.

Çevresel ve tarımsal koşullar, toprak mevcudiyeti, coğrafi konumlar, hammaddelerin seçiminde temel faktörlerdir [12]. Özellikle, biyodizel üretimi için nispeten daha ucuz ve kolay erişilebilir olması nedeniyle atık gıda yağı diğer hammaddeler arasında en çok tercih edilendir $[13,14]$.

Atık gıda yağı, otel ve kamu lokantalarında çok büyük bir sorundur $[10,15]$. Alternatif bir potansiyel yakıt olarak atık gida yapı biyodizeli ile çalışan içten yanmalı motorların performans, emisyon ve yakıt özellikleri ile ilgili çeşitli çalışmalar vardır $[11,14,16-18]$.

Geleneksel fosil yakıtların yerini alan bir başka potansiyel enerji kaynağ 1 da hidrojendir.

Hidrojen, Yanma sonrası su ürettiği için temiz ve çevre dostu enerji olmasıyla bilinir $[19,20]$.

Hidrojen doğal olarak mevcuttur ve farklı kaynaklardan da üretilebilir [21]. Literatürde, hidrojen gazı ilave yakıt katkı maddesi olarak kullanılan çeşitli çalışmalar bulunabilir [22-29].

Chelladorai ve arkadaşları [29] üzüm çekirdeği çekirdeği yağı biyodizeli ve dizel yakıtının yanma, performans ve emisyon özellikleri analiz edilmiş ve çift yakıtlı modda emme manifoldunda hidrojen indüksiyonu ile elde edilen sonuçlarla karşılaştırılmıştır. Tam yükte maksimum hidrojen payıyla üzüm çekirdeği biyodizelin nitrik oksit emisyonu \%43,61 ve duman emisyonu, hidrojen indüksiyonu olmadan biyodizele göre $\% 19,73$ daha düşük çıktığını gözlemlemişlerdir.

Saf hidrojenle zenginleştirilmiş Nar çekirdeği yağı biyodizelinin dizel motor performans ve emisyon özelliklerine etkisi Tüccar ve Uludamar [25] tarafından incelenmiştir. Deneylerde saf hidrojen ilavesinin hem motor performansinda hem de egzoz emisyonlarında küçük bir iyileşmeye neden olduğunu rapor etmişlerdir.

Özcanlı ve arkadaşları [30], hidrojen veya HHO ile zenginleştirilmiş Hint yağı metil ester-dizel karışımları ile beslenen dizel motorun performans ve emisyon özelliklerini araştırdılar. Saf hidrojenin Hint yağı metil estere eklenmesinin, egzoz gazı emisyonları üzerinde, HHO eklenmesiyle karşılaştırıldığında, pozitif bir etkisi olduğunu tespit ettiler.

Bir başka çalışmada, mikroalg biyodizel ile beslenen hidrojen ve hidroksit gaz emmeli sıkıştırma ateşleme motoru ve düşük kükürtlü dizel yakıt karışımının motor performans ve emiyon üzerine etkileri Uludamar [26] tarafindan incelenmiştir. Sonuçlar, Çalışma, mikroalg biyodizelinin hidrojen ve hidroksit gazı ilavesiyle kullanımının çevresel açıdan çok umut verici bir kombinasyon olduğunu aydınlatmıştır.

Du ve arkadaşları [20] tarafindan hidrojen direkt enjeksiyonu altında hidrojen benzini motorlarının ekonomisi ve emisyonları araştırıldı.

Serin ve Yıldızhan [30] yaptıkları çalışmada, dizel ve çay tohumu yağı biyodizel karışımlarına hidrojenle zenginleştirmenin etkileri, modifiye 
edilmemiş bir sıkıştırma ateşleme motoru üzerinde deneysel olarak incelenmiştir. Çalışmada Hidrojen zenginleştirmesi, tüm test yakıtları için $\mathrm{CO}$ ve $\mathrm{CO}_{2}$ emisyonlarını azalttığı, hidrojen yakıtının akış hızının artırılması, $\mathrm{NO}_{\mathrm{x}}$ hariç performans değerlerini ve yaydığı zararlı gazları iyileştirdiği rapor edilmiştir.

$\mathrm{Bu}$ çalışmada dizel ile çalışan bir sıkıştırma ateşleme motor, emilen hava içerisine sabit hızda hidrojen verilerek çalışabilecek şekilde uyarlanmıştır. Esas yakıt olarak dizel ve AKY biyodizeli normal yakıt sistemi ile püskürtülerek ayrı ayrı değişik hızlarda çalıştırılarak emme manifoldundan hidrojen ilavesinin performans ve emisyona etkisi incelenmiştir.

\section{MATERYAL VE YÖNTEM}

Biyodizel atık kızartma yağı kullanılarak üretilmiştir. Trigliserit içinde yüksek serbest yağ asidi içeriği varsa, alkali katalizli transesterifikasyon reaksiyonu verimli bir şekilde gerçekleşemeyecektir [31]. Yağ yüksek serbest yağ asidi (FFA) değerine sahip olduğu için, önce bir ön arıtma yöntemi olan asit katalizinin kullanılması ile indirgenmiştir.

Transesterifikasyon yönteminde, sırasıyla, katalizör ve alkol olarak sodyum hidroksit ve metanol seçilmiştir. Daha sonra, yağ, alkol ve katalizör ile karıştırıldı ve termometre, reaksiyondan önce $60{ }^{\circ} C^{\prime}$ 'lik bir sıcaklık gösterene kadar 1sıtıld1. Karışım 1 saat aynı sıcaklıkta karıştırıldı. Ham metil ester, gliserin metil esterden ayrılması için 8 saat boyunca hunide tutuldu. Ayrilan ham metil ester, 1lık suda yıkandı ve daha sonra 1 saat boyunca $105{ }^{\circ} \mathrm{C}$ 'de bir kurutma işlemine tabi tutuldu. Sonunda metil ester bir filtreden geçirildi ve saf biyodizel elde edildi. Üretimden sonra, test motorundaki deneysel yakıtın kullanılabilirliğini belirlemek için biyodizelin bazı kritik yakıt özellikleri Avrupa Standartlarına göre ölçülmüştür. Kyoto Electronics DA-130, Zeltex ZX440, IKAWerke C2000 Bomba Kalorimetre, AKV-202 Otomatik Kinematik Viskozite cihazları, sırasıyla, test yakıtlarının yoğunluğunu, setan sayısını, 1sıtma değerini (kalorifik değeri) ve viskozitesini ölçmek için kullanıldı.

\subsection{Deneysel Tasarım}

Deneysel çalışmalar, 4-zamanlı, 4 silindirli, doğal olarak emişsiz, modifiye edilmemiş bir ateşleme motoru, bir hidrolik dinamometreye bağlanmış ve motorun egzoz çıkışına bağlı herhangi bir filtre veya başka bir emisyon cihazı olmayan dizel emisyon analizörü ile gerçekleştirilmiştir. Test motorunun, hidrolik dinamometrenin ve emisyon analiz cihazının teknik özellikleri Çizelge 1'de verilmiştir. Emme manifolduna dakikada 5 litre debisinde (1/ dak) $\mathrm{H}_{2}$ gazı hava ile birlikte verilir ve motora gönderilmiştir. Deneyler tam yük koşulu altında 1200-2400 d/dk aralığında gerçekleştirilmiştir ve veriler $300 \mathrm{~d} / \mathrm{dk}$ aralıklarla toplanmıştır. Deney motorunun şeması, Şekil 1'de gösterilmiştir. Deneyler, dizel, AKY biyodizeli, dizel-hidrojen gazı ve AKY biyodizel-hidrojen gazı olmak üzere dört farklı yakıtla gerçekleştirilmiştir.

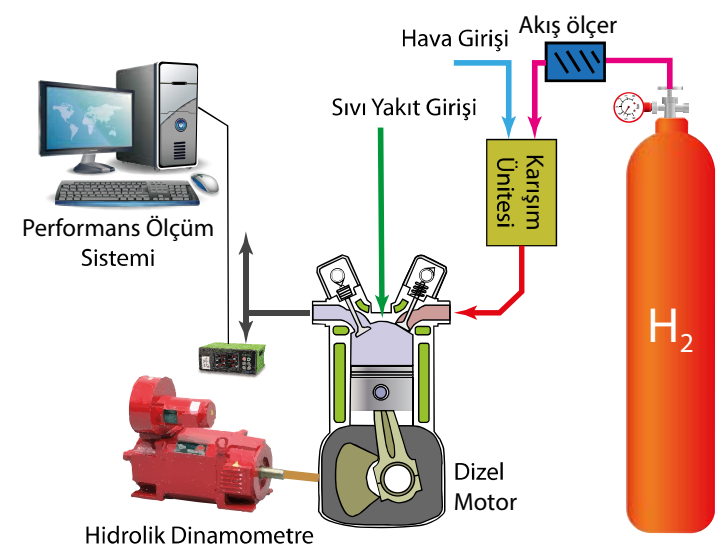

Şekil 1. Deneysel düzenek şeması

\section{BULGULAR VE TARTIŞMA}

\subsection{Yakıt Özelik Ölçümleri ve Enerji Hesaplamaları}

Yakıt özellikleri, bir motorun performans, emisyon üzerinde çok büyük öneme sahiptir. Çalışmada kullanılan test yakıtlarının ölçüm sonuçları Çizelge 2'de verilmiştir. Sonuçlar, AKY 
Çizelge 1. Test motoru / hidrolik dinamometre / emisyon analizörün teknik özellikleri

\begin{tabular}{|c|c|c|c|c|c|}
\hline \multicolumn{2}{|c|}{ Test Motoru } & \multicolumn{2}{|c|}{ Hidrolik Dinamometre } & \multicolumn{2}{|c|}{ Emisyon Analizörü } \\
\hline $\begin{array}{c}\text { Marka / } \\
\text { Model }\end{array}$ & $\begin{array}{c}\text { Mitsibushi } \\
\text { Center } \\
\text { (Test Engine)/ } \\
\text { 4D34-2A }\end{array}$ & $\begin{array}{l}\text { Marka / } \\
\text { Model }\end{array}$ & Netfren & Marka / Model & MRU / 1600V \\
\hline Tip & $\begin{array}{l}\text { Direct injection } \\
\text { diesel with } \\
\text { glow plug }\end{array}$ & $\begin{array}{c}\text { Tork / Hız } \\
\text { Aralığg }\end{array}$ & $\begin{array}{c}0-1700 \mathrm{Nm} / \\
0-7500 \mathrm{rpm}\end{array}$ & $\mathrm{CO} / \mathrm{CO}_{2} / \mathrm{O}_{2}$ & $\begin{array}{c}0-10 \% / 0-20 \% / 0- \\
22 \%\end{array}$ \\
\hline $\begin{array}{c}\text { Displaceme } \\
\text { nt / Bore }\end{array}$ & $\begin{array}{c}3907 \mathrm{cc} / 104 \\
\mathrm{~mm}\end{array}$ & $\begin{array}{c}\text { Gövde } \\
\text { çapı / tork } \\
\text { kolu } \\
\text { uzunluğu }\end{array}$ & $\begin{array}{l}250 \mathrm{~mm} / \\
250 \mathrm{~mm}\end{array}$ & $\begin{array}{c}\mathrm{NO} / \mathrm{NO}_{2} / \\
\text { Lambda }\end{array}$ & $\begin{array}{c}0-4000 \mathrm{ppm} / 0- \\
1000 \mathrm{ppm} / 0,9-99\end{array}$ \\
\hline Güç / Tork & $\begin{array}{c}89 \mathrm{~kW} @ 3200 \\
\mathrm{rpm} / 295 \\
\mathrm{Nm} @ 1800 \mathrm{rpm}\end{array}$ & Tork & $\begin{array}{c}295 \mathrm{Nm} @ \\
1800 \mathrm{rpm}\end{array}$ & Accuracy & $\begin{array}{l}\text { According to } \\
\text { OIML-class } 1\end{array}$ \\
\hline & & & & $\begin{array}{c}\text { Ortam Sicaklı̆̆ı / } \\
\text { Egzoz Gazı } \\
\text { Sicaklığı } \\
\end{array}$ & $\begin{array}{c}+50-+45^{\circ} \mathrm{C} / \mathrm{Max} \\
650^{\circ} \mathrm{C}\end{array}$ \\
\hline
\end{tabular}

Çizelge 2. Test yakıtlarının özellik ölçümlerinin sonuçları

\begin{tabular}{|c|c|c|c|c|}
\hline Yakıt Özellikleri & Dizel & EN590 & $\begin{array}{c}\text { AKY } \\
\text { Biyodizeli }\end{array}$ & EN 14214 \\
\hline Yoğunluk (20 $\left.{ }^{\mathbf{}} \mathbf{C}\right)\left(\mathbf{~ k g} / \mathbf{m}^{\mathbf{3}}\right)$ & 831 & $820-845$ & 889 & $860-900$ \\
\hline Setan Numarası & 55 & Min 51 & 52,58 & Min 51 \\
\hline Kalorifik Değer, $\mathbf{( M j} / \mathbf{k g})$ & 44,824 & - & 38,223 & - \\
\hline Kinematik Viskozite $\left.\mathbf{( 4 0}{ }^{\circ} \mathbf{C}\right)\left(\mathbf{m m}^{\mathbf{2}} / \mathbf{s}\right)$ & 2,65 & $2,00-4,5$ & 4,83 & $3,5-5,00$ \\
\hline
\end{tabular}

Çizelge 3. Enerji hesaplama sonuçları

\begin{tabular}{|c|c|c|}
\hline Test Yakitı & $\begin{array}{l}\text { Ortalam Enerji }(\mathbf{M j}) \\
\qquad \begin{array}{c}(\dot{\mathrm{E}}=\dot{\mathrm{m}} \mathrm{CV}) \\
\frac{\sum_{\mathbf{n}} \dot{\mathbf{E}}}{\mathbf{n}}\end{array}\end{array}$ & $\begin{array}{c}\text { E }\left(\mathrm{H}_{2}\right)(\%)(\text { Ortalama) } \\
\mathrm{E}\left(\mathrm{H}_{2}\right)=\frac{\dot{\mathrm{m}}_{\mathrm{H}_{2}} * \mathrm{CV}_{\mathrm{H}_{2}}}{\dot{\mathrm{m}}_{\mathrm{f}} * \mathrm{CV}_{\mathrm{f}}+\dot{\mathrm{m}}_{\mathrm{H}_{2}} * \mathrm{CV}_{\mathrm{H}_{2}}}\end{array}$ \\
\hline Dizel & 12058 & - \\
\hline Diesel - $\mathbf{H}_{2}(5 \mathrm{l} / \mathrm{m})$ & $12562+2,952$ & 0,023 \\
\hline AKY biyodizeli & 12310 & - \\
\hline $\begin{array}{c}\text { AKY Biyodizeli }-\mathbf{H}_{2} \\
(5 \mathrm{l} / \mathrm{m})\end{array}$ & $12033+2,952$ & 0,024 \\
\hline \multicolumn{3}{|c|}{$\mathrm{P}_{\mathrm{b}}=2 \pi N T, \mathrm{BSFC}=\frac{\dot{\mathrm{m}}}{\mathrm{P}_{\mathrm{b}}}$} \\
\hline
\end{tabular}


değeri ve daha yüksek viskozite gibi geleneksel konvansiyonel dizel yakıtla karşılaştırıldığında bazı dezavantajlara sahip olduğunu göstermiştir. Deney sonuçları, AKY biyodizelinin kalorifik değerinin, geleneksel dizel yakıttan \%13,18 daha düşük olduğunu göstermiştir.

Kalorifik değer, motorda yakıldığında yakıtın enerji katkısını belirler. $\mathrm{Bu}$ problem $\mathrm{H}_{2}$ 'nin zenginleştirilmesiyle ele alınabilir. Ayrıca, $\mathrm{H}_{2}$ yakıtlarındaki karbon atomlarının yokluğu ek bir avantajdır. Çizelge 3'te yakıtların enerji katkısı verilmiştir.

Enerji hesaplamaları, fren özgül yakıt tüketimi (brake specific fuel consumption, BSFC) sonuçlarına göre gerçekleştirildi. Hesaplamalar yakıtı $\mathrm{H}_{2}$ ile zenginleştirmenin silindirlere doldurulmuş yakıtın küçük bir enerji oranını verdiğini göstermektedir. $\mathrm{H}_{2}$ gazı dizel ve biyodizel yakıtı (120 Mj/kg) ile karşılaştırıldığında çok yüksek kalorifik değere sahiptir, ancak düşük enerji tüketimi $(0,082)$ [32] $\mathrm{H}_{2}$ düşük enerji katkısı oranının ana sebebidir.

\subsection{Performans ve Emisyon Karekteristikleri}

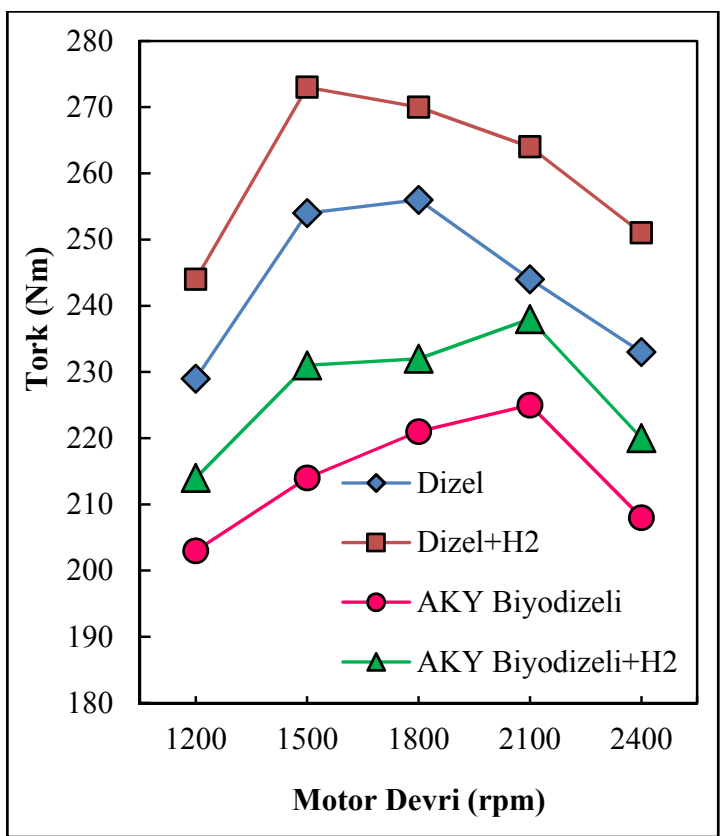

Şekil 2. Motor torku ve motor devri

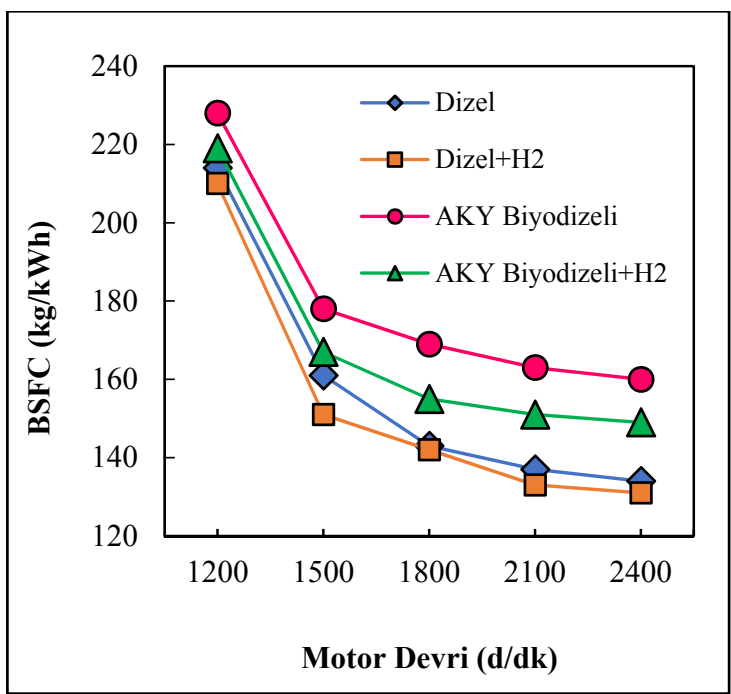

Şekil 3. BSFC ve motor devri

Şekil 2 ve 3'de motor torku ve BSFC (özgül yakıt tüketimi) ölçüm sonuçları farklı motor hızlarında gösterilmiştir. Sonuçlar açıkça hem dizel ve hem de biyodizel yakıtlar için $\mathrm{H}_{2}$ zenginleştirmenin performans karakteristiğini geliştirdiğini göstermektedir. Küçük bir enerji katkısıyla bile, $\mathrm{H}_{2}$ gazının üstün yanma özelliklerinin, BSFC değerlerini azalttığı gözlemlenmiştir. Tüm ortalama ölçümlere göre biyodizel kullanımı ile BSFC \%13,81 arttığ zenginleşmesinin, dizel ve AKY biyodizeli için BSFC değerlerini sırasıyla $\% 2,78$ ve $\% 6,34$ azalttığını ortaya koymuştur.

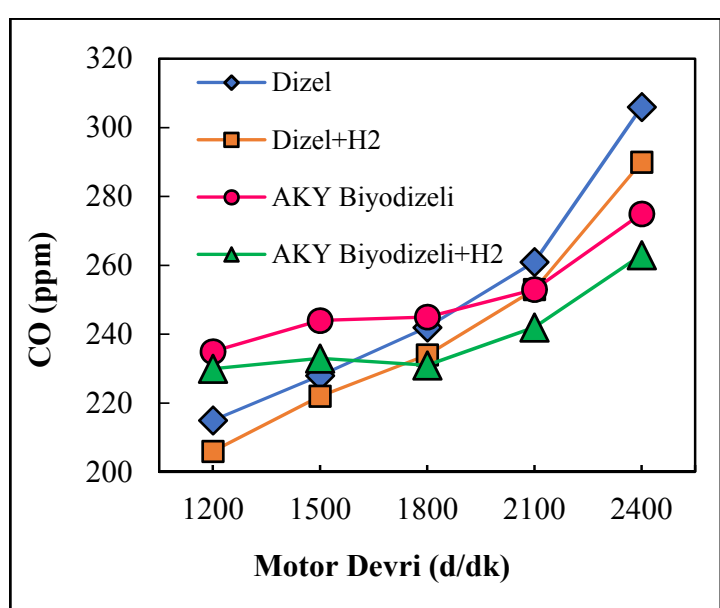

Şekil 4. CO emisyonları 


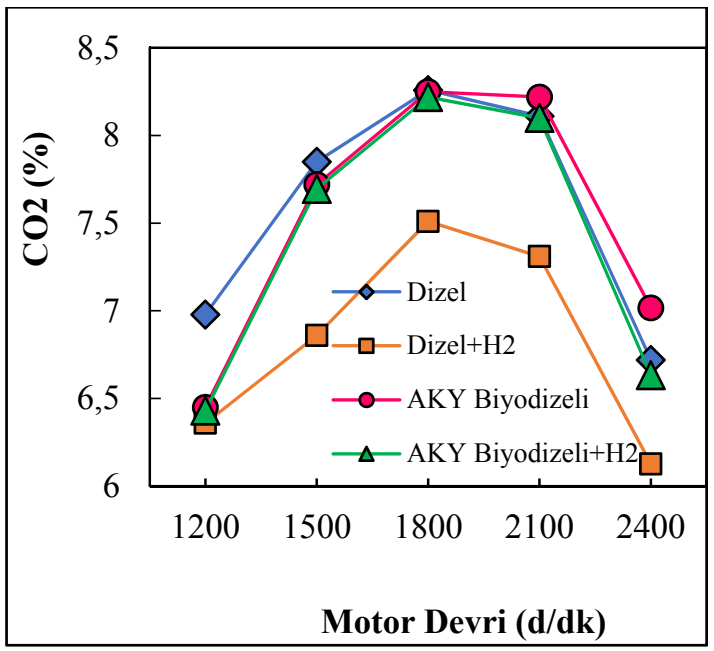

Şekil 5. $\mathrm{CO}_{2}$ emisyonları

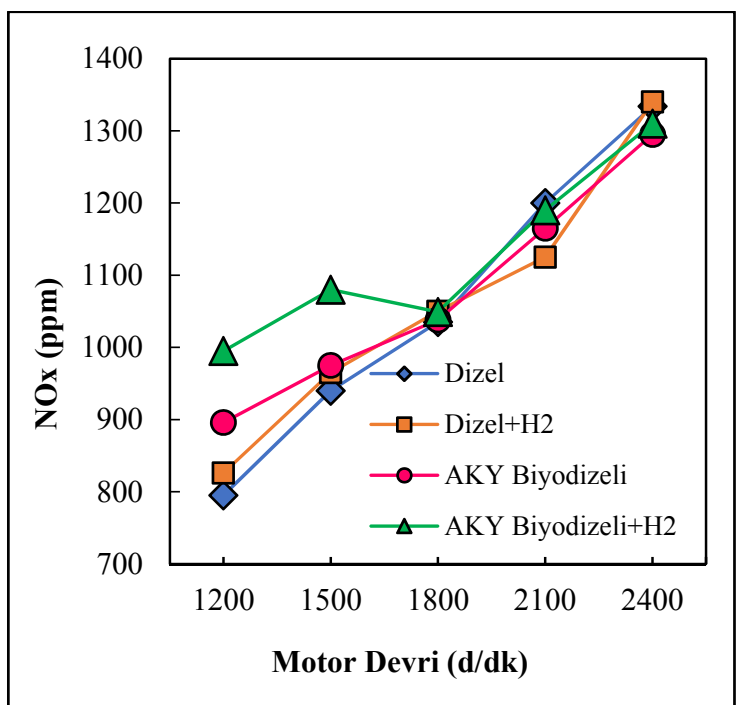

Şekil 6. $\mathrm{NO}_{\mathrm{x}}$ emisyonları

Şekil 4-6, test motorunun egzoz emisyon ölçüm sonuçlarının grafikleridir. Sonuçlar, $\mathrm{H}_{2}$ zenginliğinin karbon atomlarının yokluğu ve $\mathrm{H}_{2}$ gazının iyi yanma özelliklerine bağlı olarak $\mathrm{CO}$ ve $\mathrm{CO}_{2}$ emisyonlarını azalttığını açıkça göstermektedir. Aksine, $\mathrm{H}_{2}$ ilavesi, $\mathrm{H}_{2}$ yanması durumunda silindir içi sıcaklığın artması nedeniyle $\mathrm{NO}_{\mathrm{x}}$ emisyonlarını artırdı. Ölçümler, sırasıyla $\mathrm{H}_{2}$ gazı ile zenginleştirilmiş yakıtlar için dizel ve AKY biyodizeli için CO emisyonlarında $\% 3,75$ ve $\% 4,23$ oranında azalmaya neden olmuştur. Ayrıca $\mathrm{H}_{2}$ zenginleştirmesi, sırasıyla dizel ve AKY biyodizeli için $\mathrm{CO}_{2}$ emisyonunu \%9,89 ve \%2,26 azaltmıştır. $\mathrm{NO}_{\mathrm{x}}$ emisyonları, dizel AKY biyodizeline kıyasla, sırasıyla $\mathrm{H}_{2}$ ile zenginleştirilmiş yakıtlar için sırasılyla, $\% 1,13$ ve $\% 4,74$ olmuştur.

\section{SONUÇLAR}

$\mathrm{Bu}$ çalışmanın amacı, $\mathrm{H}_{2}$ zenginleştirmesinin dizel ve AKY biyodizeli üzerindeki performansının, bir sıkıştırma ateşleme motorunun emisyon karakteristiğine olan etkilerini gözlemlemektir. Ayrıca, motorun titreşim seviyesini etkileyen emme manifoldundan AKY biyodizel ve hidrojen ilavesinin etkileri araştırılmıştır.

Deneyde elde edilen sonuçlar aşağıda verilmiştir.

- $\mathrm{H}_{2}$ zenginleştirme performansı artırır ve fren özgül yakıt tüketimini azaltır.

- $\mathrm{H}_{2}$ zenginleştirmesi $\mathrm{CO}$ ve $\mathrm{CO}_{2}$ emisyonlarını azaltır ve $\mathrm{NO}_{\mathrm{x}}$ emisyonlarını artırır.

\section{KAYNAKLAR}

1. Hoseini, S.S., Najafi, G., Ghobadian, B., Mamat, R., Sidik, N.A.C., Azmi, W.H., 2017. The Effect of Combustion Management on Diesel Engine Emissions Fueled with Biodieseldiesel Blends. Renewable and Sustainable Energy Reviews, 73, 307-331.

2. Çalık, A., 2018. Determination of Vibration Characteristics of a Compression İgnition Engine Operated by Hydrogen Enriched Diesel and Biodiesel Fuels. Fuel, 230, 355-358.

3. Çalık, A., 2017. Pamuk Yağı Biyodizelinin Motor Ses Seviyesine Olan Etkilerinin İncelenmesi. Çukurova Üniversitesi Mühendislik-Mimarlık Fakültesi Dergisi, 32(4), 147-152.

4. Tüccar, G., 2018. Environmental Effects Effect of Hydroxy Gas Enrichment on Vibration, Noise and Combustion Characteristics of a Diesel Engine Fueled with Foeniculum Vulgare oil Biodiesel and Diesel Fuel. Energy Sources, Part A: Recovery, Utilization, and Environmental Effects, 40(10), 1257-1265. 
5. Musa, I.A., 2016. The Effects of Alcohol to Oil Molar Ratios and the Type of Alcohol on Biodiesel Production Using Transesterification Process. Egyptian Journal of Petroleum, 25(1), 21-31.

6. Uludamar, E., Yildizhan, Ş., Aydin, K., Özcanli, M., 2016. Vibration, Noise and Exhaust Emissions Analyses of an Unmodified Compression Ignition Engine Fuelled with Low Sulphur Diesel and Biodiesel Blends with Hydrogen Addition. International Journal of Hydrogen Energy, 41(26), 11481-11490.

7. Zhou, J.H., Cheung, C.S., Leung, C.W., 2014. Combustion, Performance, Regulated and Unregulated Emissions of a Diesel Engine with Hydrogen Addition. Applied Energy, 126, 1-12.

8. Ramadhas, A.S., Jayaraj, S., Muraleedharan, C., Padmakumari, K., 2006. Artificial Neural Networks Used for the Prediction of the Cetane Number of Biodiesel. Renewable Energy, 31(15), 2524-2533.

9. Yildizhan, Ş., Uludamar, E., Çalık, A., Dede, G., Özcanl1, M., 2017. Fuel Properties, Performance and Emission Characterization of Waste Cooking Oil (WCO) in a Variable Compression Ratio (VCR) Diesel Engine. European Mechanical Science, 1(2), 56-62.

10. Zareh, P., Zare, A.A., Ghobadian, B., 2017. Comparative Assessment of Performance and Emission Characteristics of Castor, Coconut and Waste Cooking Based Biodiesel as Fuel in a Diesel Engine. Energy, 139, 883-894.

11. Senthur Prabu, S., Asokan, M.A., Roy, R., Francis, S., Sreelekh, M.K., 2017. Performance, Combustion and Emission Characteristics of Diesel Engine Fuelled with Waste Cooking Oil Bio-diesel/diesel Blends with Additives. Energy, 122, 638-648.

12. Rehan, M., Gardy, J., Demirbas, A., Rashid, U., Budzianowski, W.M., Pant, D., Nizami, A.S., 2017. Waste to Biodiesel: A Preliminary Assessment for Saudi Arabia. Bioresource Technology.

13. Atabani, A.E., Silitonga, A.S., Ong, H.C., Mahlia, T.M.I., Masjuki, H.H., Badruddin, I.A., Fayaz, H., 2013. Non-edible Vegetable Oils: A Critical Evaluation of Oil Extraction, Fatty Acid Compositions, Biodiesel Production, Characteristics, Engine Performance and
Emissions Production. Renewable and Sustainable Energy Reviews, 18, 211-245.

14. Hwang, J., Bae, C., Gupta, T., 2016. Application of Waste Cooking Oil (WCO) Biodiesel in a Compression İgnition Engine. Fuel, 176, 20-31.

15. Tan, Y.H., Abdullah, M.O., Nolasco-Hipolito, C., Zauzi, N.S.A., Abdullah, G.W., 2017. Engine Performance and Emissions Characteristics of a Diesel Engine Fueled with Diesel-biodiesel-bioethanol Emulsions. Energy Conversion and Management, 132, 54-64.

16. Attia, A.M.A., Hassaneen, A.E., 2016. Influence of Diesel Fuel Blended with Biodiesel Produced from Waste Cooking Oil on Diesel Engine Performance. Fuel, 167, 316-328.

17. Cheung, C.S., Man, X.J., Fong, K.W., Tsang, O.K., 2015. Effect of Waste Cooking Oil Biodiesel on the Emissions of a Diesel Engine. Energy Procedia, 66, 93-96.

18. Elshaib, A.A., Kamal, M.M., Elahwany, A.A., 2014. Performance of a Diesel Engine Fueled by Waste Cooking Oil Biodiesel. Journal of the Energy Institute, 87(1), 11-17.

19. Arat, H.T., Sürer, M.G., 2017. State of Art of Hydrogen Usage as a Fuel on Aviation. European Mechanical Science, 2(1), 20-30.

20. Du, Y., Yu, X., Liu, L., Li, R., Zuo, X., Sun, Y., 2017. Effect of Addition of Hydrogen and Exhaust Gas Recirculation on Characteristics of Hydrogen Gasoline Engine. International Journal of Hydrogen Energy, 42(12), 8288-8298.

21. Çelebi, K., Uludamar, E., Özcanlı, M., 2017. Evaluation of Fuel Consumption and Vibration Characteristic of a Compression Ignition Engine Fuelled with High Viscosity Biodiesel and Hydrogen Addition. International Journal of Hydrogen Energy, 42(36), 23379-23388.

22. Nguyen, T.A., Mikami, M., 2013. Effect of Hydrogen Addition to Intake Air on Combustion Noise from a Diesel Engine. International Journal of Hydrogen Energy, 38(10), 4153-4162.

23. Chiriac, R., Apostolescu, N., 2013. Emissions of a Diesel Engine Using B20 and Effects of Hydrogen Addition. International Journal of Hydrogen Energy, 38(30), 13453-13462.

24. Bhasker, J.P., Porpatham, E., 2017. Effects of Compression Ratio and Hydrogen Addition on 
Lean Combustion Characteristics and Emission Formation in a Compressed Natural Gas Fuelled Spark Ignition Engine. Fuel, 208, 260-270.

25. Tüccar, G., Uludamar, E., 2017. Emission and Engine Performance Analysis of a Diesel Engine Using Hydrogen Enriched Pomegranate Seed Oil Biodiesel. International Journal of Hydrogen Energy, 43, 18014-18019.

26. Uludamar, E., 2018. Effect of Hydroxy and Hydrogen Gas Addition on Diesel Engine Fuelled with Microalgae Biodiesel. International Journal of Hydrogen Energy, 43(38), 18028-18036.

27. Baltacioğlu, M.K., Arat, H.T., Kenanoğlu, R., 2017. Exergy and Performance Analysis of a CI Engine Fuelled with HCNG Gaseous Fuel Enriched Biodiesel. International Journal of Exergy, 24, 39-56.

28. Rimkus, A., Matijošius, J., Bogdevičius, M., Bereczky, Á., Török, Á., 2018. An Investigation of the Efficiency of Using $\mathrm{O}_{2}$ and $\mathrm{H}_{2}$ (hydrooxile gas -HHO) Gas Additives in a ci Engine Operating on Diesel Fuel and Biodiesel. Energy, 152, 640-651.

29. Chelladorai, P., Varuvel, E.G., Martin, L.J., Bedhannan, N., 2018. Synergistic Effect of Hydrogen Induction with Biofuel Obtained from Winery Waste (Grapeseed Oil) for CI Engine Application. International Journal of Hydrogen Energy, 43(27), 12473-12490.

30. Serin, H., Yildizhan, Ş., 2018. Hydrogen Addition to Tea Seed Oil Biodiesel: Performance and Emission Characteristics. International Journal of Hydrogen Energy, 43, 18020-18027.

31. Canakci, M., Ozsezen, N., 2005. Evaluating Waste Cooking Oils as Alternative Diesel Fuel. G.U. Journal of Science, 18(1), 81-91.

32. Rocha, H.M.Z., Pereira, R. da S., Nogueira, M.F.M., Belchior, C.R.P., Tostes, M.E. de L., 2017. Experimental Investigation of Hydrogen Addition in the Intake Air of Compressed Ignition Engines Running on Biodiesel Blend. International Journal of Hydrogen Energy, 42(7), 4530-4539. 